Review

\title{
ProEx C as Diagnostic Marker for Detection of Urothelial Carcinoma in Urinary Samples: A Review
}

\author{
Gerardo Botti ${ }^{1}$, Maria Gabriella Malzone ${ }^{1,2}$, Elvira La Mantia1, 2, Micaela Montanari2, 3, Daniela Vanacore ${ }^{2}$ \\ Sabrina Rossetti2, 4, Vincenzo Quagliariello2, 4, Carla Cavaliere2, 5, Rossella Di Franco 2, 6, Luigi Castaldo 2, 7, \\ Gianluca Ametrano 2, 6, Francesca Cappuccio 2, 8, Francesco Jacopo Romano², Raffaele Piscitelli2, 9, Maria \\ Filomena Pepe1, 2, Carmine D'Aniello2,10 and Gaetano Facchini ${ }^{4}$ \\ 1. Pathology and Cytopathology Unit, National Cancer Institute "Fondazione G. Pascale", 80131 Naples, Italy; \\ 2. Progetto ONCONET 2.0 - Linea progettuale 14 per l'implementazione della prevenzione e diagnosi precoce del tumore alla prostata e testicolo - Regione \\ Campania, Italy \\ 3. Department of Molecular Medicine and Medical Biotechnologies, University of Naples "Federico II", 80100 Naples, Italy; \\ 4. Division of Medical Oncology, Department of Uro-Gynaecological Oncology, National Cancer Institute "Fondazione G. Pascale", 80131 Naples, Italy; \\ 5. Department of Onco-Ematology Medical Oncology, S.G. Moscati Hospital of Taranto, Taranto, Italy; \\ 6. Radiation Oncology, National Cancer Institute "Fondazione G. Pascale", 80131 Naples, Italy; \\ 7. Division of Urology, Department of Uro-Gynaecological Oncology, National Cancer Institute "Fondazione G. Pascale", 80131 Naples, Italy; \\ 8. Psicology Unit, National Cancer Institute "Fondazione G. Pascale", 80131 Naples, Italy; \\ 9. Pharmacy Unit, National Cancer Institute "Fondazione G. Pascale", 80131 Naples, Italy; \\ 10. Division of Medical Oncology, A.O.R.N. dei COLLI “Ospedali Monaldi-Cotugno-CTO”, Naples, Italy.
}

$\triangle$ Corresponding author: Dr. Maria Gabriella Malzone, Pathology and Cytopathology Unit, National Cancer Institute "Fondazione G. Pascale", via Mariano Semmola, 80131 Napoli, Italy. Tel/Fax: +390815903849 E-mail: gabriellamalzone@hotmail.com

(c) Ivyspring International Publisher. This is an open access article distributed under the terms of the Creative Commons Attribution (CC BY-NC) license (https://creativecommons.org/licenses/by-nc/4.0/). See http://ivyspring.com/terms for full terms and conditions.

Received: 2016.10.12; Accepted: 2016.12.20; Published: 2017.04.21

\begin{abstract}
The gold standard for the detection of urothelial carcinoma is represented by urethro-cystoscopy and biopsy. Both procedures are invasive and expensive and therefore cytology is often used as first approach to investigate on a possible neoplasia, being a safe and cost-effective diagnostic modality of evaluation. Because cytology alone is not highly sensitive for detection of low grade urothelial carcinoma and recurrence of the disease, several adjunct markers and urine based tests for urothelial carcinoma have been developed, which can help in the final diagnosis. In particular, ProEx $C$ is an immunohistochemical cocktail containing antibodies direct against topoisomerase Ila (TOP2A) and minichromosome maintenance 2 (MCM2) proteins. It proved to be a valid biomarker especially in detecting squamous intraepithelial lesions in cervical liquid-based samples and in discerning these lesions from their mimickers, as well as in ovarian, endometrial, vulvar, primary and metastatic melanomas, breast, pancreatic and renal cell carcinomas. This brief review covers the effective utility of ProEx $C$ as adjunct tool in assessing the urothelial lesions in urine cytology, also providing prognostic and therapeutic information to help in clinical decisions.
\end{abstract}

Key words: ProEx C biomarker; urothelial carcinoma; urine cytology samples.

\section{Introduction}

Urothelial carcinoma (UC) is one the most common malignancies derived from the urothelium of the lower urinary tract. Every year approximately 380000 new cases of UC occur in the world, with an estimated 15210 deaths from disease [1]. At initial diagnosis, most UCs are non-muscle invasive and the prognosis for these patients is generally good. Cancers will recur in $30-80 \%$ of cases, with a progression to muscle invasive disease of $1-45 \%$ within 5 year $[2,3]$. The accurate diagnosis is crucial for the appropriate management and routinary controls for UC are necessary once the diagnosis is made [4-7]. Urethro-cystoscopy, which is best for detecting low-grade urothelial carcinoma (LGUC), and urine cytology as supplement, often the test that recognizes high-grade urothelial carcinoma (HGUC) 
are the current approaches for the initial detection and follow-up of UCs. Imaging of the upper urinary tract is carried out as a further primary investigation and for follow-up in high risk cases [2], as urothelial carcinoma can be also found in the renal pelvis or ureter. Both cystoscopy and biopsy are invasive and pricey procedures and therefore cytology is often used as first approach to investigate on a possible neoplasia, being a safe and cost-effective diagnostic modality of evaluation $[8,9]$.

Routinary cytopathology can be very challenging in discerning neoplasia/dysplasia from reactive changes of urothelial cells: the morphology of the cells may overlap [10] and the diagnosis can be difficult when the tumor cells are few and/or degenerate [11]. It is even more difficult to diagnose a dysplasia in those cases in which urothelial atypia is observed in some cells but not all the morphological criteria are met for the cases to be classified as carcinoma [11-14]. Thus, the identification of atypical cell changes is of great importance for the correct management of these patients. However, urine cytology is operator dependent and the sensitivity for the detection of urothelial neoplasms is highly variable, as reported in the existing literature $[15,16]$.

In patients with HGUC cytology has shown high sensitivity and specificity, whereas, in those patients with LGUC, the estimate of false-positives and false-negatives can be $>10 \%[17,18]$. Applying strict cytomorphological criteria to distinguish low grade lesions from reactive cells, the detection of false-negatives can be substantially improved $[17,19]$. The general opinion is that the only cytological approach is not sufficient for identifying the recurrence of the disease [20]. Multiple markers and urine based tests for UC have been developed [21-28], which can help in the differential diagnosis [29-31]. Urine is in contact with the urothelium of the entire urinary tract and therefore a biomarker for detecting recurrence of the disease in urine samples would be preferable, especially if it could avoid the use of more invasive and expensive procedures [32].

This short review will focus on the employment of ProEx C marker as ancillary test to improve detection of UC in urine cytology specimens.

\section{The ProEx C biomarker}

ProEx C (BD Diagnostics-TriPath, Burlington, North Carolina) is an immunohistochemical cocktail containing antibodies against topoisomerase IIa (TOP2A) and minichromosome maintenance 2 (MCM2) proteins. TOP2A is a nuclear enzyme that controls and alters the state of DNA during transcription, occurring in processes such as chromosome condensation, chromatid separation and the relief of DNA torsional stress. This enzyme catalyzes the temporal breaking and rejoining of two strands of DNA, thus altering the DNA structure. The gene encoding TOP2A is the target for numerous anticancer agents; mutations in this gene have been related with the development of drug resistance [33]. MCM2 protein is a key component of the pre-replication complex and may be involved in the formation of replication forks and in the recruitment of other DNA replication related proteins [4]. Deregulation of MCM2 function has been suggested to contribute to tumorigenesis [6]. Both TOP2A and MCM2 are over-expressed in the cell nucleus during aberrant $\mathrm{S}$-phase induction of human papillomavirus (HPV)-infected cells [7, 8, 34-36].

Several studies have confirmed the over-expression of ProEx C especially in cervical squamous dysplasia [9, 37-41]. Guo and collaborators investigated on the efficacy of p16 and ProExC in detecting high-grade cervical intraepithelial neoplasia (CIN 2+) and cervical carcinoma [42]. The more severe was the cervical lesion, the more p16 and ProExC were positive. p16 immunostaining was more sensitive (79\% for CIN 2+; $90 \%$ for CIN 3+) than ProExC (67\% for CIN 2+; $84 \%$ for CIN 3+), whereas for CIN 3+ lesions, ProExC showed a specificity higher than p16. The highest specificity ( $100 \%$ for CIN $2+$; $93 \%$ for $\mathrm{CIN} \mathrm{3+)} \mathrm{was} \mathrm{found} \mathrm{in} \mathrm{samples} \mathrm{with}$ positivity of both biomarkers (p16+/ProExC+), suggesting that the combination these two biomarkers can be very useful to discriminate CIN 2/3 from its mimics. Furthermore, Siddiqui investigated on the utility of ProEx C for detecting CIN2+ lesions and compared it with high-risk HPV (hr-HPV) status in patients with ASC-US cytology: ProEx C showed a higher sensitivity compared to hr-HPV $(98.04 \%$ and $82.35 \%$, respectively), whereas the specificity was not statistically significant $[9,34]$.

ProEx C immunostaining was also performed on formalin-fixed, paraffin-embedded histological sections for distinguishing HSIL from adenocarcinoma and from various non-neoplastic glandular lesions, such as microglandular hyperplasia, tubal metaplasia, cervical endometriosis, reactive endocervix and atrophy [43, 44]. ProEx C showed a higher sensitivity, specificity, positive and negative predictive value in well-defined neoplastic lesions (high-grade squamous intraepithelial lesion/adenocarcinoma in situ (AIS)), compare to non-neoplastic lesions (squamous metaplasia/ reactive benign endocervix) [7]. The distribution of immunostaining for AIS was different from all benign mimics, but the intensity of staining for AIS overlapped with some mimics as it was not significantly different from endometriosis, 
microglandular hyperplasia and reactive endocervix [45]. These studies suggest that, although ProEx C is a valuable marker for distinguishing squamous and endocervical lesions of the cervix from reactive benign changes, caution should always be taken into account when using this marker in evaluating hyperchromatic crowded groups in Papanicolaou-stained gynecological smears.

Walts and Bose proved positive staining (>50\%) for ProEx C in Paget cells, in all cases of Paget's disease irrespective of tissue site (extramammary, mammary), albeit it appeared that the immunostaining could be unrelated to HPV [46]. ProEx $C$ is a useful proliferation marker for high-grade vulvar intraepithelial neoplasia analogous to the staining patterns reported in high-grade cervical intraepithelial neoplasia, which is essentially limited to the basal and parabasal layers of the epithelium [37]. Similarly, ProEx C seems to be helpful in distinguishing melanoma from benign nevi, although ProEx $\mathrm{C}$ does not have prognostic significance in disease-specific survival in patients with primary melanoma [47].

\section{ProEx $\mathrm{C}$ as urine marker in the detection of urothelial carcinoma}

Minichromosome maintenance protein 2 (MCM2) and minichromosome maintenance protein 5 (MCM5) have been previously investigated as immunoassays in urothelial carcinoma [48-50]. A mini review by Stoeber and collaborators in 1999 reported on the possible use of MCM5 as a non-invasive, immunochemical method for the detection of UC on urinary cytological samples [50].
Numerous adjunct markers, such as CK20, p53, CD44, p16, thrombomodulin, Ki67, UroVysion and ImmunoCyt/uCyt have been evaluated as possible ancillary tests in cases of atypical urothelial cells (AUC) [31, 48, 51-53]. In particular, uCyt and UroVysion are the two ancillary tests most frequently used on exfoliative urothelial cytology. These two assays are not always processed and analyzed by cytotechnologists and/or cytopathologists, but their diagnostic evaluation requires trained and certified personnel. Besides, these tests are time-consuming and more costly to perform [54]. The first published study using ProEx C in urinary cytology [55] showed that ProEx $C$ was very useful in stratifying patients with diagnosis of atypical urothelial cells into benign and malignant subsets. In a follow-up comparative study, ProEx $C$ showed a high sensitivity in detecting HGUC (92\%) (Figure 1A) and a low sensitivity in LGUC (72\%) (Figure 1B). On histological sections of HGUC, ProEx C staining involves the whole thickness of the neoplastic epithelium (Figure 2A) in contrast to LGUC where the reaction is only focal and closer to the basal layers (Figure 2B). Therefore, the positive cells may not reach the surface for exfoliation into the urine. This observation may explain the lower sensitivity of ProEx C in LGUC [56]. Vergara-Lluri and colleagues in their study [57] demonstrated that the combination of ProEx C and uCyt ancillary tests greatly improved the sensitivity in detecting LGUCs (94\%). In fact, cytology alone has a low sensitivity (5-18\%) in LGUCs cases [58]. Moreover, they noted an remarkable sensitivity (92\%) in detecting HGUCs using ProEx $\mathrm{C}$ alone or in combination with $\mathrm{uCyt}$.
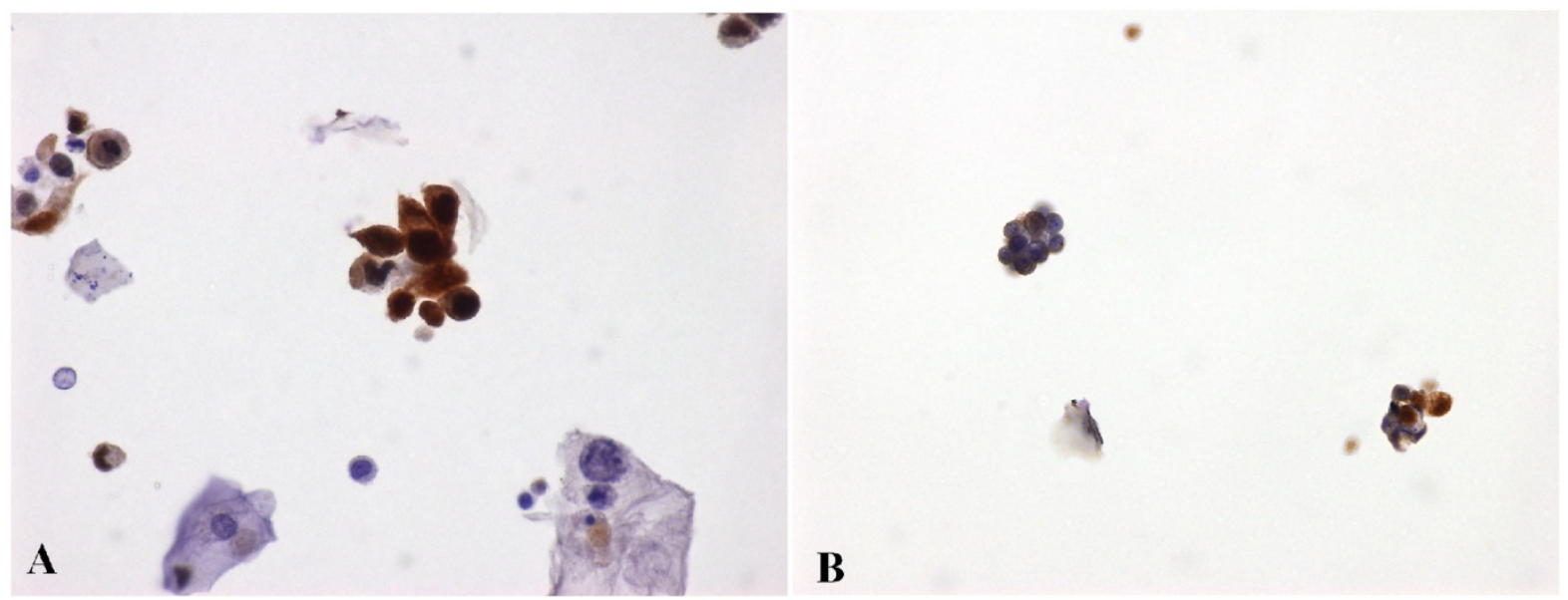

Figure 1. ProEx C immunostaining. A) High Grade Urothelial Carcinoma (HGUC) - voided urine. Degenerated malignant cells display characteristic variation in cellular size, NC ratio, cytoplasmic shapes and nuclear irregularity. Some nuclei are huge, hyperchromatic and the chromatin is unevenly distributed. These cells are admixed with benign squamous cells. Clusters of malignant high grade urothelial cells are also seen. ProEx $\mathrm{C}$ markedly stains both isolated and clusters of malignant cells. (ProEx C, x60 magnification). B) Low Grade Urothelial Carcinoma (LGUC) - voided urine. Two small papillary clusters of cells with relatively small NC ratios, minimal nuclear atypia and overlapping. ProEx $C$ immunostaining shows a patchy positivity. (ProEx C, x40 magnification) 


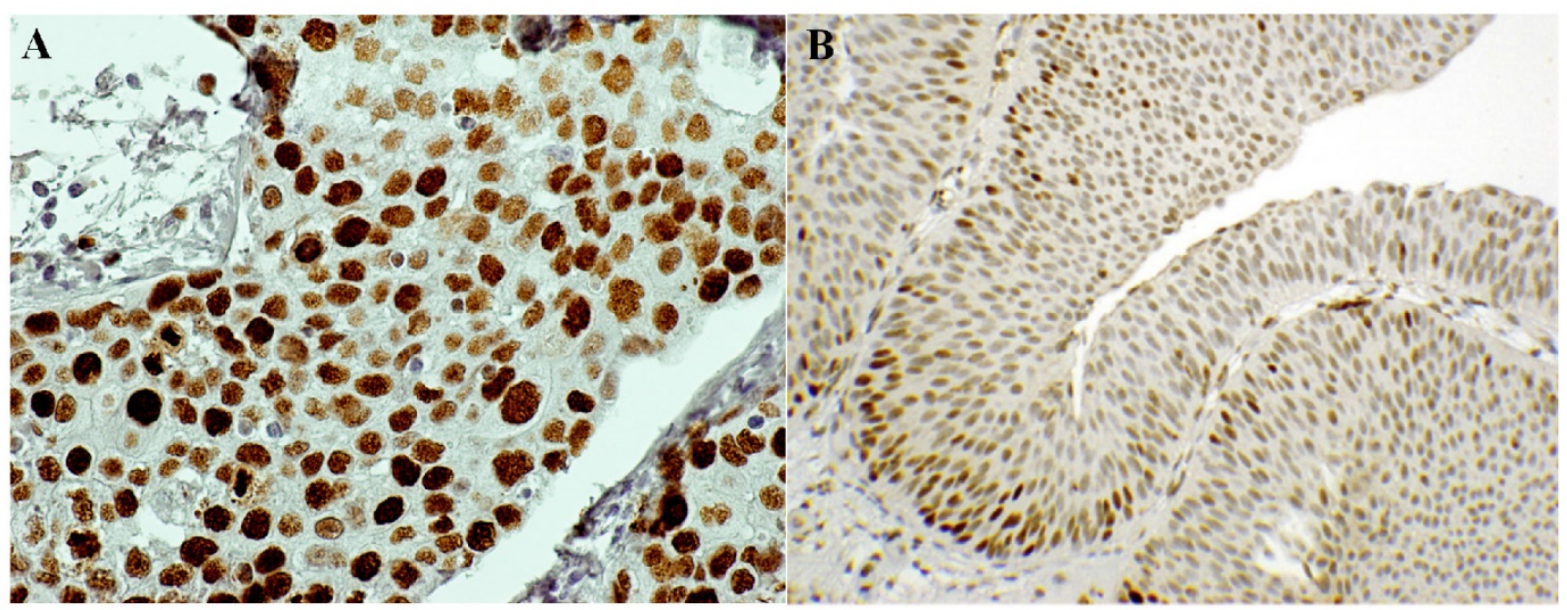

Figure 2. ProEx C immunostaining. A) High Grade Urothelial Carcinoma (HGUC) - bladder biopsy. ProEx C is highly positive (score 3+) in the whole thickness of the neoplastic epithelium. (ProEx C, x60 magnification). B) Low Grade Urothelial Carcinoma (LGUC) - bladder biopsy. ProEx C immunostaining shows a patchy positivity: at the basal layers a score $2+$ has been assigned, at the superficial layer a score $1+$. (ProEx C, x20 magnification).

To distinguish carcinoma in situ (CIS) from reactive atypia, McKenney and colleagues used a panel of three antigens: cytokeratin 20, p53, and CD44 [10]. Their original work showed p53 positivity in $81 \%$, CK20 over-expression in $57 \%$ and absence of CD44 reactivity in all cases of CIS. Furthermore, they showed that a diffuse, full-thickness staining with CD44 together with p53 over-expression and absence of CK20 would suggest more a reactive process. McKenney and his collaborators concluded that a combination of morphology and a panel of these 3 antibodies would be ideal to distinguish reactive from malignant urothelium. A study carried out by Yin and colleagues [59] showed that all cases of CIS of their series exhibited $100 \%$ reactivity with p16 immunostaining and a $71 \%$ in invasive UCs. Moatamed and his collaborators [56], instead, found a $100 \%$ of ProEx C reactivity in both CIS and invasive UC. It appears that for the identification of urothelial lesions, ProEx $\mathrm{C}$ alone will provide good sensitivity and specificity, rather than a panel of markers. Burger and colleagues [48] used MCM2 antibody, one of the antibodies in the ProEx C cocktail, in histological samples to evaluate the risk of recurrence in bladder cancer. Its positive or negative reaction is more accurate than CK20, Ki-67 and histologic grade in the prediction of the recurrence of the disease.

Liu and collaborators measured the expression of ProEx $\mathrm{C}$ in primary and metastatic UC, also comparing it with thrombomodulin immuhistochemical staining [60]. Both ProEx C and thrombomodulin had similar sensitivity for metastatic UC ( $84 \%$ vs. $77 \%)$, whereas ProEx C yielded a higher sensitivity for primary UC than thrombomodulin ( $93 \%$ and $72 \%$ respectively). This study demonstrated that ProEx C is useful for diagnosing primary UC but not helpful for detecting metastatic carcinoma, as it shows moderate to high expression in most of the common carcinomas such as colon, prostatic, renal cell, stomach, breast and lung carcinomas. Metastatic carcinomas can be seen in urine cytology specimens too, although very rarely [61]. Finally, Chang and colleagues, compared the utility of ProEx C and UroVysion in urine specimens [54]. They showed that ProEx $C$ results were comparable to those previously published [55, 57]: ProEx C displays a higher sensitivity than UroVysion for identifying UCs (88.9-55.6\% respectively). In addition, positive predictive value $(88.9 \%)$ and negative predicted value $(77.8 \%)$ were much higher for ProEx $C$ than those observed for UroVysion (64.3 and 30.8\% respectively).

\section{Conclusions}

Urothelial carcinoma is an important health problem worldwide because of its silent clinical evolution, incidence and high recurrence rate. Conventional surveillance requires cystoscopy and urinary cytology. Unfortunately, cystoscopy is an invasive procedure for patients and very expensive for health care assistance. Urine cytology, although is a simple, safe and cost-effective diagnostic method of investigation, it is not highly sensitive for detection of LGUC. A wide range of non-invasive techniques have been evaluated that can improve early diagnosis, efficiency and costs of follow-up. Urinary biomarkers may also help to estimate and characterize bladder malignancies evolution. ProEx $\mathrm{C}$ seems to be a promising and simple adjunct device in urine cytology, especially in urine samples with either scant cellularity or with only a few atypical cells present, which can lead to cytological misinterpretation. ProEx C concretely differentiates high-grade lesions from benign reactive conditions; it helps to resolve queries 
regarding low-grade versus high grade UC, but it is not a useful marker in identifying metastatic UC, being also expressed in colon, stomach, breast and lung carcinomas. In conclusion, future investigations, using much larger series, will be necessary to further support and solidify these early promising findings.

\section{Abbreviations}

UC: Urothelial carcinoma; LGUC: low-grade urothelial carcinoma; HGUC: high-grade urothelial carcinoma; HPV: human papillomavirus; CIN: cervical intraepithelial neoplasia; hr-HPV: high-risk HPV; ASC-US: atypical squamous cells of undetermined significance; AIS: adenocarcinoma in situ; CIS: carcinoma in situ.

\section{Acknowledgments}

The authors gratefully acknowledge the technical assistance of Dr. Antonella Gioioso and Dr. Anna Cipolletta Campanile.

\section{Competing Interests}

The authors have declared that no competing interest exists.

\section{References}

1. Parkin DM, Bray F, Ferlay J, Pisani P. Global cancer statistics, 2002. CA Cancer J Clin. 2005; 55: 74-108.

2. Babjuk M, Oosterlinck W, Sylvester R, Kaasinen E, Böhle A, Palou-Redorta J. EAU guidelines on non-muscle-invasive urothelial carcinoma of the bladder. Eur Urol. 2008; 54: 303-14.

3. Sylvester RJ, van der Meijden APM, Oosterlinck W, Witjes JA, Bouffioux C, Denis L, Newling DW, Kurth K. Predicting recurrence and progression in individual patients with stage Ta T1 bladder cancer using EORTC risk tables: a combined analysis of 2596 patients from seven EORTC trials. Eur Urol. 2006; 49: 466-77.

4. Lei M, Tye BK. Initiating DNA synthesis: from recruiting to activating the MCM complex. J Cell Sci 2001; 114(Pt 8):1447-1454.

5. Freeman A, Morris LS, Mills AD, Stoeber K, Laskey RA, Williams $\mathrm{GH}$, Coleman N. Minichromosome maintenance proteins as biological markers of dysplasia and malignancy. Clin Cancer Res. 1999; 5: 2121-2132.

6. Lei M. The MCM complex: its role in DNA replication and implications for cancer therapy. Curr Cancer Drug Target. 2005; 5: 365-380.

7. Malinowski DP. Molecular diagnostic assays for cervical neoplasia: emerging markers for the detection of high-grade cervical disease. BioTechniques. 2005; 38(Suppl 4):S17-S23.

8. Malinowski DP. Multiple biomarkers in molecular oncology. I. Molecular diagnostics applications in cervical cancer detection. Expert Rev Mol Diagn. 2007; 7: 117-131.

9. Siddiqui MT, Cohen C, Nassar A. Detecting high-grade cervical disease on ASC-H cytology: role of BD ProEx C and Digene Hybrid Capture II HPV DNA testing. Am J Clin Pathol. 2008; 130: 765-770.

10. McKenney JK, Desai S, Cohen C, Amin MB. Discriminatory immunohistochemical staining of urothelial carcinoma in situ and non-neoplastic urothelium: an analysis of cytokeratin 20, p53, and CD44 antigens. Am J Surg Pathol. 2001; 25: 1074-8.

11. Murphy WM, Busch C, Algaba F. Intraepithelial lesions of urinary bladder: morphologic considerations. Scand J Urol Nephrol Suppl. 2000; 205: 67-81.

12. Epstein JI, Amin MB, Reuter VR, Mostofi FK. The World Health Organization/International Society of Urological Pathology consensus classification of urothelial (transitional cell) neoplasms of the urinary bladder. Am J Surg Pathol. 1998; 22(12):1435-48.

13. McKenney JK, Gomez JA, Desai S, Lee MW, Amin MB. Morphologic expression of urothelial carcinoma in situ: a detailed evaluation of its histologic patterns with emphasis on carcinoma in situ with microinvasion. Am J Surg Pathol. 2001; 25(3):356-62.

14. Milord RA, Lecksell K, Epstein JI. An objective morphologic parameter to aid the diagnosis of flat urothelial carcinoma in situ. Hum Pathol. 2001; 32(9):997-1002.
15. Shenoy UA, Colby TV, Schumann GB. Reliability of urinary cytodiagnosis in urothelial neoplasms. Cancer. 1985; 56: 2041-5.

16. Raab SS, Lenel JC, Cohen MB. Low grade transitional cell carcinoma of the bladder. Cytologic diagnosis by key features as identified by logistic regression analysis. Cancer. 1994; 74: 1621-6.

17. Maier $U$, Simak R, Neuhold N. The clinical value of urinary cytology: 12 years of experience with 615 patients. J Clin Pathol. 1995; 48: 314-7.

18. Murphy WM. Current status of urinary cytology in the evaluation of bladder neoplasms. Hum Pathol. 1990; 21: 886-96.

19. Hughes JH, Raab SS, Cohen MB. The cytologic diagnosis of low-grade transitional cell carcinoma. Rev Pathol Cytopathol. 2000; 114(Suppl):S59-S67.

20. Ross JS, Cohen MB. Ancillary Methods for the Detection of Recurrent Urothelial Neoplasia. Cancer Cytopathol. 2000; 90(2):75-86

21. van Rhijn BWG, van der Poel HG, van der Kwast ThH. Urine markers for bladder cancer surveillance. A systematic review. Eur Urol. 2005; 47: 736-48.

22. van der Poel HG, Debruyne FMJ. Can biological markers replace cystoscopy? An update. Curr Opin Urol. 2001; 11: 503-9.

23. Glas AS, Roos D, Deutekom M, Zwinderman AH, Bossuyt PMM, Kurth KH. Tumor markers in the diagnosis of primary bladder cancer. A systematic review. J Urol. 2003; 169: 1975-82.

24. Lokeshwar VB, Habuchi T, Grossman HB, Murphy WM, Hautmann $\mathrm{SH}$ Hemstreet GP 3rd, Bono AV, Getzenberg RH, Goebell P, Schmitz-Dräger BJ, Schalken JA, Fradet Y, Marberger M, Messing E, Droller MJ. Bladder tumor markers beyond cytology: International Consensus Panel on bladder tumor markers. Urology. 2005; 66(Suppl 6A):S35-S63.

25. Hajdinjak T. UroVysion FISH test for detecting urothelial cancers: meta-analysis of diagnostic accuracy and comparison with urinary cytology testing. Urol Oncol. 2008; 26: 646-51.

26. Konety B, Lotan Y. Urothelial bladder cancer: biomarkers for detection and screening. BJU Int. 2008; 102: 1234-41.

27. Zwarthoff EC. Detection of tumours of the urinary tract in voided urine. Scand J Urol Nephrol Suppl. 2008; 42: 147-53.

28. Vrooman OPJ, Witjes JA. Urinary markers in bladder cancer. Eur Urol. 2008; 53: 909-16.

29. Farrow GM. Urine cytology in the detection of bladder cancer: a critical approach. J Occup Med. 1990; 32: 817-821.

30. Sullivan PS, Nooraie F, Sanchez H, Hirschowitz S, Levin M, Rao PN, Rao J. Comparison of Immuno-Cyt, UroVysion, and urine cytology in detection of recurrent urothelial carcinoma: a "split-sample" study. Cancer. 2009; 117: 167-173.

31. Sullivan PS, Chan JB, Levin MR, Rao J. Urine cytology and adjunct markers for detection and surveillance of bladder cancer. Am J Transl Res. 2010; 2: 412-440.

32. Noon AP, Zlotta AR. Urothelial bladder cancer urinary biomarkers. JIFCC. 2014; 25(1):99-114.

33. 1. Champoux JJ. DNA topoisomerases: structure, function, and mechanism. Annu Rev Biochem. 2001; 70: 369-413.

34. Siddiqui MT, Hornaman K, Cohen C, Nassar A. ProEx C immunocytochemistry and high-risk human papillomavirus DNA testing in papanicolaou tests with atypical squamous cell (ASC-US) cytology: correlation study with histologic biopsy. Arch Pathol Lab Med. 2008; 132: 1648-52.

35. Tambouret RH, Misdraji J, Wilbur DC. Longitudinal clinical evaluation of a novel antibody cocktail for detection of high-grade squamous intraepithelial lesions on cervical cytology specimens. Arch Pathol Lab Med. 2008; 132: 918-25.

36. Kong CS, Beck AH, Longacre TA. A panel of 3 markers including p16, ProExC, or HPV ISH is optimal for distinguishing between primary endometrial and endocervical adenocarcinomas. Am J Surg Pathol. 2010; 34: 915-26.

37. Chen $\mathrm{H}$, Gonzalez JL, Brennick JB, Liu M, Yan S: Immunohistochemical patterns of proex c in vulvar squamous lesions: Detection of overexpression of mcm2 and top2a. Am J Surg Pathol. 2010; 34(9):1250-1257.

38. Kelly D, Kincaid E, Fansler Z, Rosenthal DL, Clark DP. Detection of cervical high-grade squamous intraepithelial lesions from cytologic samples using a novel immunocytochemical assay (ProEx C). Cancer. 2006; 108: 494-500.

39. Pinto AP, Schlecht NF, Woo TY, Crum CP, Cibas ES. Biomarker (ProEx C, p16(INK4A), and MiB-1) distinction of high-grade squamous intraepithelial lesion from its mimics. Mod Pathol. 2008; 21: 1067-1074.

40. Badr RE, Walts AE, Chung F, Bose S. BD ProEx C: a sensitive and specific marker of HPV-associated squamous lesions of the cervix. Am J Surg Pathol. 2008; 32: 899-906.

41. David O, Cabay RJ, Pasha S, et al. The role of deeper levels and ancillary studies (p16(Ink4a) and ProExC) in reducing the discordance rate of Papanicolaou findings of high-grade squamous intraepithelial lesion and follow-up cervical biopsies. Cancer. 2009; 117: 157-66.

42. Guo M, Baruch AC, Silva EG, Jan YJ, Lin E, Sneige N, Deavers MT. Efficacy of p16 and ProExC immunostaining in the detection of high-grade cervical intraepithelial neoplasia and cervical carcinoma. Am J Clin Pathol. 2011; 135: 212-20.

43. Sanati S, Huettner P, Ylagan LR. Role of ProExC: a novel immunoperoxidase marker in the evaluation of dysplastic squamous and glandular lesions in cervical specimens. Int J Gynecol Pathol. 2010; 29: 79-87.

44. Aximu D, Azad A, Ni R, Colgan T, Nanji S. A pilot evaluation of a novel immunohistochemical assay for topoisomerase II-alpha and minichromosome maintenance protein 2 expression (ProEx C) in cervical adenocarcinoma in situ, adenocarcinoma, and benign glandular mimics. Int J Gynecol Pathol. 2009; 28: 114-119. 
45. Santin AD, Zhan F, Bignotti E, Siegel ER, Cané S, Bellone S, Palmieri M, Anfossi S, Thomas M, Burnett A, Kay HH, Roman JJ, O'Brien TJ, Tian E, Cannon MJ, Shaughnessy J Jr, Pecorelli S. Gene expression profiles of primary HPV 16 and HPV 18 infected early stage cervical cancers and normal cervical epithelium: identification of novel candidate biomarkers for cervical cancer diagnosis and therapy. Virology. 2005; 331: 269-291.

46. Walts $\mathrm{AE}$, Bose $\mathrm{S}$. Bd ProEx $\mathrm{C}$ immunostaining in extramammary paget's disease and perineal melanoma. Mod Pathol. 2009; 22(2):246-251.

47. Yan S, Coffing BN, Li Z, Xie H, Brennick JB, Beg HA, Froehlich HM, Wells WA. Diagnostic and Prognostic Value of ProEx C and GLUT1 in Melanocytic Lesions. Anticancer Res. 2016; 36: 2871-2880.

48. Burger M, Denzinger S, Hartmann A, Wieland WF, Stoehr R, Obermann EC. $\mathrm{Mcm} 2$ predicts recurrence hazard in stage $\mathrm{Ta} / \mathrm{T} 1$ bladder cancer more accurately than CK20, Ki67 and histological grade. Br J Cancer. 2007; 96(11):1711-1715.

49. Kruger S, Thorns C, Stocker W, Müller-Kunert E, Böhle A, Feller AC. Prognostic value of MCM2 immunoreactivity in stage T1 transitional cell carcinoma of the bladder. Eur Urol. 2003; 43(2):138-145

50. Stoeber K, Halsall I, Freeman A, Swinn R, Doble A, Morris L, Coleman $\mathrm{N}$, Bullock N, Laskey RA, Hales CN, Williams GH. Immunoassay for urothelial cancers that detects DNA replication protein Mcm5 in urine. Lancet. 1999; 354(9189):1524-1525.

51. Halling KC, Kipp BR. Fluorescence in situ hybridization in diagnostic cytology. Hum Pathol. 2007; 38(8):1137-1144.

52. Soyuer I, Sofikerim M, Tokat F, Soyuer S, Ozturk F. Which urine marker test provides more diagnostic value in conjunction with standard cytology-ImmunoCyt/uCytp or cytokeratin 20 expression. Diagn Pathol. 2009; 4:20. doi:10.1186/1746-1596-4-20.

53. Li HX, Li M, Li CL, Ma JH, Wang MR, Rao J, Pan QJ. ImmunoCyt and cytokeratin 20 immunocytochemistry as adjunct markers for urine cytologic detection of bladder cancer: a prospective study. Anal Quant Cytol Histol. 2010; 32(1):45-52.

54. Chang S, Smith E, Levin M, Rao J-Y and Moatamed NA. Comparative study of ProEx C immunocytochemistry and UroVysion fluorescent in-situ hybridization assays on urine cytology specimens. Cytojournal. 2015; 12:2. doi: 10.4103/1742-6413.149845.

55. Moatamed NA, Rao JY, Alexanian S, Cobarrubias M, Levin M, Lu D, Apple SK. ProEx $\mathrm{C}$ as an adjunct marker to improve cytological detection of urothelial carcinoma in urinary specimens. Cancer Cytopathol. 2013; 121(6):320-328.

56. Moatamed NA, Vergara-Lluri ME, Lu D, Apple SK, Kerkoutian S, Rao JY. Utility of ProEx $C$ in the histologic evaluation of the neoplastic and nonneoplastic urothelial lesions. Hum Pathol. 2013; 44: 2509-17.

57. Vergara-Lluri ME, Hu E, Rao JY, Levin M, Apple SK, Moatamed NA. Comparative evaluation of ProEx C and ImmunoCyt/uCyt assays in atypical urine cytology. Arch Pathol Lab Med. 2014; 138: 1215-22.

58. Greene KL, Berry A, Konety BR. Diagnostic utility of the ImmunoCyt/uCytp test in bladder cancer. Rev Urol. 2006; 8(4):190-197.

59. Yin M, Bastacky S, Parwani AV, McHale T, Dhir R. p16INK4 immunoreactivity is a reliable marker for urothelial carcinoma in situ. Hum Pathol. 2008; 39: 527-35.

60. Liu L, Cohen C, Siddiqui MT. Expression of ProEx C in Primary and Metastatic Urothelial Carcinoma. Diagn Cytopathol. 2015; 43(3):181-187

61. Bardales RH, Pitman MB, Stanley MW, Korourian S, Suhrland MJ. Urine cytology of primary and secondary urinary bladder adenocarcinoma. Cancer. 1998; 84: 335-343. 